\title{
A mobile restriction modification system consisting of methylases on the IncA/C plasmid
}

\author{
Ruibai Wang ${ }^{*}$ (D) Jing Lou and Jie Li
}

\begin{abstract}
Background: IncA/C plasmids play important roles in the development and dissemination of multidrug resistance in bacteria. These plasmids carry three methylase genes, two of which show cytosine specificity. The effects of such a plasmid on the host methylome were observed by single-molecule, real-time (SMRT) and bisulfite sequencing in this work.

Results: The results showed that the numbers of methylation sites on the host chromosomes were changed, as were the sequences recognized by MTase. The host chromosomes were completely remodified by the plasmid with a methylation pattern different from that of the host itself. When the three $\mathrm{dcm}$ genes were deleted, the transferability of the plasmid into other Vibrio cholerae and Escherichia coli strains was lost. During deletion of the $\mathrm{dcm}$ genes, except for the wild-type strains and the targeted deletion strains, 18.7\% 38.5\% of the clones lost the IncA/C plasmid and changed from erythromycin-, azithromycin- and tetracycline-resistant strains to strains that were sensitive to these antibiotics.
\end{abstract}

Conclusions: Methylation of the InCA/C plasmid was a new mobile restriction modification (RM) barrier against foreign DNA. By actively changing the host's methylation pattern, the plasmid crossed the barrier of the host's RM system, and this might be the simplest and most universal method by which plasmids acquire a broad host range. Elimination of plasmids by destruction of plasmid stability could be a new effective strategy to address bacterial multidrug resistance.

Keywords: Methylation, Vibrio cholerae, IncA/C plasmid, Cytosine-specific DNA methylase, Restriction modification system, Multidrug resistance

\section{Background}

Antibiotic resistance, especially multidrug resistance, is a serious challenge worldwide. Many bacterial drug resistance genes are stored in plasmids and can be horizontally transferred to other bacteria. The IncA/C family plasmids are major members of these plasmids [1,2]. Both of the famous plasmids, namely, pIP1202, which exhibits high resistance to at least eight antibiotics and was isolated from Yersinia pestis in 1995 [3], and the NDM-1 plasmid, which was isolated from superresistant bacteria in India, Bangladesh, Pakistan, Britain and the United States in

\footnotetext{
* Correspondence: wangruibai@icdc.cn

State Key Laboratory for Infectious Disease Prevention and Control, National Institute for Communicable Disease Control and Prevention, Chinese Center for Disease Control and Prevention, Changbai Road 155, Changping, Beijing 102206, People's Republic of China
}

August 2010 [4], are IncA/C plasmids. These plasmids have generated much concern with regard to public health and bioterrorism. IncA/C plasmids have the ability to robustly accumulate antibiotic resistance genes. There are many resistance genes against rifampicin, erythromycin, streptomycin, chloramphenicol, sulfonamides and disinfectants that are routinely harbored on these plasmids [5], in addition to a variety of beta-lactamase genes harbored by the pNDM-1_Dok01, pNDM102337, pNDM10469, pNDM 10505, pNDMCFuy, pNDM-KN and pNDM-US plasmids of Escherichia coli and Klebsiella pneumoniae. The pVC211 plasmid that we isolated from Vibrio cholerae has 16 antibiotic resistance-related genes, including five macrolide resistance genes that utilize three mechanisms [6]. The IncA/C plasmid made $99 \%$ of Chinese $V$. cholerae $\mathrm{O} 139$ 
strains resistant to more than three antibiotics, and $47 \%$ resistant to eight antibiotics [7].

Another striking feature of the IncA/C plasmids is their wide host range. These plasmids exist and are transferred horizontally in many bacterial species and genera, such as E. coli, Salmonella, Enterobacter, Klebsiella, V. cholerae, Yersinia, Pantoea, Edwardsiella, Citrobacter freundii, Photobacterium damselae, Aeromonas, Xenorhabdus nematophila, and Providencia, with transformation efficiencies as high as $10^{-1}$ to $10^{-2}$. In addition, the skeleton of the IncA/C plasmid is also widely distributed in agricultural multidrug-resistant pathogens. Strains carrying IncA/C plasmids have been isolated from cows, chickens, turkeys and pigs. Reports have shown that the blaCMY-2 gene on the IncA/C plasmid that confers resistance to cephalosporin could be identified in human E. coli and Klebsiella pneumoniae isolates several years after the prevalence of the gene in edible animals [8]. Moreover, 1\% of E. coli strains isolated from healthy people who had never taken antibiotics were positive for the repA/C gene, the replicator of the IncA/C plasmid $[9,10]$. This mobile reservoir of drug resistance genes can transmit multidrug resistance phenotypes from foodborne pathogens to human pathogens, which demonstrates that the use of veterinary drugs can affect human drug resistance profiles, and the IncA/C plasmids have special public health implications.

IncA/C plasmids are large, conjugative plasmids that are approximately $150 \mathrm{~kb}$ in length. On the plasmid backbones, there are three methylation-related genes: $d c m 1, d c m 2$, and $d c m 3$, which are $1626 \mathrm{bp}, 1428 \mathrm{bp}$ and $924 \mathrm{bp}$ in length and are identical to the NCBI reference sequences WP 000201432.1, WP_000936896.1 and WP_000501488.1, respectively. The $d c m 1$ gene encodes Gammaproteobacteria cytosine-C5 specific DNA methylase (MTase) of the Pfam PF00145 family. The $d c m 2$ gene is a DNA cytosine methyltransferase with an AdoMet_MTase (cl17173) conserved domain. The $d c m 3$ gene is a DNA modification MTase that lacks any known conserved domain. These three methylation genes are broadly conserved in IncA $/ C_{2}$ plasmids, although a few plasmids have lost the $d c m 2$ gene due to a deletion event associated with the ARI-B resistance island [2]. There are six methylation-related genes in the host genome of $V$. cholerae: three adenine-specific MTases (dam: VC1769, VC2118, and VC2626), two rRNA MTases (VC2697 and VCA0627), and one orphan cytosine MTase, vchM (VCA0158). Generally, DNA (cytosine-5-specific) MTase (Dcm) recognizes the CCWGG motif and covalently adds a methyl group at the C5 position of the second cytosine, while Dam introduces a methyl group at the N6 position of the adenine in the GATC motif. The MTases encoded in the $V$. cholerae chromosomes are mainly Dam MTases, and the only Dcm MTase, VchM, recognizes a novel target, the first $5^{\prime} \mathrm{C}$ on both strands of the palindromic sequence $5^{\prime}$-RCC GGY-3', and leaves all 5'-CCWGG-3' sites unmethylated in $V$. cholerae [11]. These data suggest that the changes in DNA methylation mediated by the IncA/C plasmids may be different from those in the host chromosomes.

DNA methylation is a central epigenetic modification in various cellular processes, including DNA replication and repair [12], transcriptional modulation, lowering of transformation frequency, and stabilization of short direct repeats in certain bacteria; in addition, DNA methylation is necessary for site-directed mutagenesis [13]. DNA methylation acts either alone or as a part of the bacterial restriction modification (RM) system that protects the host from infection of foreign DNA and bacteriophages by degrading nonmethylated DNA with sequence-specific restriction enzymes. Although the role of IncA/C plasmids in drug resistance is well elucidated, the role of the $d c m$ genes on $\mathrm{A} / \mathrm{C}_{2}$ plasmids remains largely unexplored. In this study, the IncA/C plasmid pVC211 (148,456 bp) [6] was conjugated into $V$. cholerae strain C6706. Genome-wide bisulfite sequencing and single-molecule, real-time (SMRT) sequencing $[14,15]$ were conducted to provide a global view of the changes in the methylation patterns of the host DNA that were induced by this plasmid.

\section{Results}

\section{Methylomes determined by SMRT sequencing}

The two samples, C6706 and CV2, produced 998,990,159 bp and 1,097,369,564 bp polymerase reads, respectively, in SMRT sequencing, and the average sequencing coverage reached $250 x$. In the C6706 genome, 1,476,420 methylation sites were detected, and 1490,035 methylation sites were detected in CV2. Although the actual sequencing coverages were much higher than the coverage required for ${ }^{\mathrm{m} 5} \mathrm{C}$ analysis by PacBio RS II, the confidence of detection was not high enough, leading to failure of ${ }^{\mathrm{m} 5} \mathrm{C}$ detection. In addition to the ${ }^{\mathrm{m} 4} \mathrm{C}$ and ${ }^{\mathrm{m} 6} \mathrm{~A}$ sites, a large proportion of methylation sites, including ${ }^{\mathrm{m} 5} \mathrm{C}$, in both $\mathrm{C} 6706$ and $\mathrm{CV} 2$ were reported as 'modified bases' and failed to show definitive methylation patterns in SMRT analysis. The number of ${ }^{\mathrm{m} 4} \mathrm{C}$ and ${ }^{\mathrm{m} 6} \mathrm{~A}$ methylation sites, whether intergenic or in coding sequences (CDSs), decreased after the transformation of the pVC211 plasmid, but the number of untyped methylation sites increased by 18,763 sites, resulting in a slight increase in the total methylation rate from $36.6 \%$ in C6706 to 36.94\% in CV2 (Table 1).

There were 4013 annotated genes on the $V$. cholerae chromosome, including 2775 functional genes, 25 rRNA genes, and 94 tRNA genes distributed on chromosome I and 1115 functional genes and 4 tRNA genes distributed on chromosome II (Table 2). The methylation patterns on the two chromosomes of $V$. cholerae were considerably different. The genes on chromosome I were generally 
Table 1 Methylation information derived from SMRT sequencing

\begin{tabular}{|c|c|c|c|c|c|c|c|c|c|c|c|}
\hline & \multicolumn{2}{|c|}{ Total methylation sites } & \multicolumn{3}{|l|}{${ }^{\mathrm{m} 4} \mathrm{C}$} & \multicolumn{3}{|l|}{${ }^{\mathrm{m} 6} \mathrm{~A}$} & \multicolumn{3}{|l|}{ Untyped } \\
\hline & C6706 & $\mathrm{CV} 2$ & C6706 & $\mathrm{CV} 2$ & Difference & C6706 & CV2 & Difference & C6706 & CV2 & Difference \\
\hline CDS & 192,116 & 187,228 & 151,109 & 146,542 & -4567 & 41,007 & 40,686 & -321 & & & \\
\hline Intergenic & 5594 & 5407 & 4362 & 4209 & -153 & 1232 & 1198 & -34 & & & \\
\hline Total & $1,475,558$ & $1,490,035$ & 155,471 & 151,472 & -3999 & 42,239 & 41,952 & -287 & $1,277,848$ & $1,296,611$ & $+18,763$ \\
\hline Modification ratio (\%) & 36.58 & 36.94 & 3.85 & 3.76 & -0.09 & 1.05 & 1.04 & -0.01 & 31.68 & 32.14 & 0.46 \\
\hline
\end{tabular}

methylated, dominated by ${ }^{\mathrm{m} 4} \mathrm{C}-{ }^{\mathrm{m} 6} \mathrm{~A}$ double methylation, and sites involving ${ }^{\mathrm{m} 4} \mathrm{C}$ and ${ }^{\mathrm{m} 6} \mathrm{~A}$ accounted for $84.7 \%$ (3401/4013) of the total genes. On the other hand, more than half of the genes on chromosome II exhibited non- ${ }^{\mathrm{m} 4} \mathrm{C}$ non- ${ }^{\mathrm{m} 6} \mathrm{~A}$ methylation. In particular, the methylation of the tRNA gene was the most significantly different between the two chromosomes, with 92 of the 94 genes on chromosome I involved in the methylation of ${ }^{\mathrm{m} 4} \mathrm{C}$ or ${ }^{\mathrm{m} 6} \mathrm{~A}$, while on chromosome II, only one of the four genes, VC_At2, was ${ }^{\mathrm{m} 4} \mathrm{C}$ methylated. Chromosome II of $V$. cholerae is a mega-plasmid ameliorated to the host chromosome as a result of its long-standing presence in the host lineage [16]. The differences in the methylation patterns of chromosome II also demonstrate its heterogeneity with chromosome I. However, there was no obvious difference between C6706 and CV2 in terms of the methylation patterns of the two chromosomes.

However, the methylation sites on the genomes of C6706 and CV2 showed significant changes after conjugation of the IncA/C plasmid (Table 3). A total of 124,571 sites, consisting of $85,972{ }^{\mathrm{m} 4} \mathrm{C}$ and $38,599{ }^{\mathrm{m} 6} \mathrm{~A}$ sites, in 3341 genes kept the same methylation type between the two samples. C6706 had 67,545 methylation sites that differed from CV2, and CV2 had 62,657 specific methylation sites. These differential sites accounted for 37.46 and $35.16 \%$ of the C6706 and CV2 methylation sites, respectively, involving approximately $81 \%$ of the total genes ( $97 \%$ of the total genes on chromosome I and $40 \%$ on chromosome II). This large-scale methylation change made it impossible to discern any gene function modification preference. Among the genes with differential methylation sites, the methylation modes of 116 genes changed significantly (Additional file 1: Table S2); for example, the methylation pattern of
VC_0025 changed from ${ }^{\mathrm{m} 4} \mathrm{C}-{ }^{\mathrm{m} 6} \mathrm{~A}$ double methylation to ${ }^{\mathrm{m} 4} \mathrm{C}$ single methylation, that of VC_A0698 changed from ${ }^{\mathrm{m} 4} \mathrm{C}$ methylation to ${ }^{\mathrm{m} 6} \mathrm{~A}$ methylation, and that of VC_1030 changed from ${ }^{\mathrm{m} 4} \mathrm{C}$ methylation to non- ${ }^{\mathrm{m} 4} \mathrm{C}$ non- ${ }^{\mathrm{m} 6} \mathrm{~A}$ methylation. Although 64 genes encoded hypothetical proteins with unknown function, other differentially methylated genes involved many key processes in the lifecycle of the $V$. cholerae host. These genes included the following: 1 LuxR family transcriptional regulator; 3 LysR family transcriptional regulators; 5 regulatory proteins related to phosphoglycerate transport, cold shock, sigma-54 dependent transcription, response and mannitol metabolism; Hcp-1, which is involved in chromosome segregation; 7 transport and binding proteins related to $\mathrm{Na}+\mathrm{H}+$, vibriobactin and enterobactin transportation; and 5 proteins related to protein synthesis and cell fate.

Analysis of the motif sequences using the P_MotifFind Module of SMRT further revealed the effects of the plasmid-encoded MTases on the methylation status of the host chromosomes (Table 4). Eleven and ten motifs were detected in C6706 and CV2, respectively, but only 6 motifs were commonly detected in both samples, and these shared motifs also showed significant differences in number and proportion between the two samples. Four motifs found in C6706, namely, AGKNNNNW, GADNDGCG, GARVNNDG, and TVVVNNDG, were changed to ABN BMVBW, GANNDBBG, GARVNRNG and TNVVNNDG in CV2, respectively. The DCAGVHRNG motif that was present in C6706 disappeared in CV2. These data indicate that plasmid transformation not only changed the methylation types of the host chromosomes, but also changed the characteristics of the identification sequences of the MTases.

Table 2 Methylation patterns of the two chromosomes of C6706 and CV2

\begin{tabular}{|c|c|c|c|c|c|c|c|c|c|c|}
\hline \multirow[t]{2}{*}{ Chromosome } & \multirow{2}{*}{$\begin{array}{l}\text { Gene } \\
\text { code }\end{array}$} & \multirow{2}{*}{$\begin{array}{l}\text { Gene } \\
\text { number }\end{array}$} & \multicolumn{2}{|c|}{ Single ${ }^{\mathrm{m} 4} \mathrm{C}$} & \multicolumn{2}{|c|}{ Single ${ }^{\mathrm{m} 6} \mathrm{~A}$} & \multicolumn{2}{|c|}{${ }^{\mathrm{m} 4} \mathrm{C}$ and ${ }^{\mathrm{m} 6} \mathrm{~A}$} & \multicolumn{2}{|c|}{ none ${ }^{\mathrm{m} 4} \mathrm{C} /{ }^{\mathrm{m} 6} \mathrm{~A}$} \\
\hline & & & C6706 & $\mathrm{CV} 2$ & C6706 & $\mathrm{CV} 2$ & C6706 & $\mathrm{CV} 2$ & $\mathrm{C6706}$ & $\mathrm{CV} 2$ \\
\hline \multirow[t]{3}{*}{ I } & VC & 2775 & 157 & 165 & 2 & 6 & 2602 & 2588 & 14 & 16 \\
\hline & $V C_{-} r$ & 25 & 8 & 6 & 0 & 0 & 17 & 19 & 0 & 0 \\
\hline & $V C_{-} t$ & 94 & 48 & 52 & 0 & 1 & 42 & 39 & 2 & 2 \\
\hline \multirow[t]{3}{*}{$\|$} & VC_A & 1115 & 177 & 186 & 8 & 8 & 339 & 331 & 591 & 590 \\
\hline & VC_At & 4 & 1 & 1 & 0 & 0 & 0 & 0 & 3 & 3 \\
\hline & Total & 4013 & 391 & 410 & 10 & 15 & 3000 & 2977 & 610 & 611 \\
\hline
\end{tabular}


Table 3 Common and differential ${ }^{\mathrm{m} 4} \mathrm{C}$ and ${ }^{\mathrm{m} 6} \mathrm{~A}$ methylation sites in CDS between $\mathrm{C} 6706$ and $\mathrm{CV} 2$

\begin{tabular}{|c|c|c|c|c|c|c|c|c|c|c|c|}
\hline \multirow[t]{3}{*}{ Chromosome } & \multirow[t]{3}{*}{ Gene code } & \multirow[t]{3}{*}{ Gene number } & \multicolumn{3}{|c|}{ Common methylation sites } & \multicolumn{6}{|c|}{ Differential methylation sites } \\
\hline & & & \multirow[t]{2}{*}{$\mathrm{m} 4 \mathrm{C}$} & \multirow[t]{2}{*}{$\mathrm{m} 6 \mathrm{~A}$} & \multirow{2}{*}{$\begin{array}{l}\text { Total number } \\
\text { (involved genes) }\end{array}$} & \multicolumn{2}{|l|}{$\mathrm{m} 4 \mathrm{C}$} & \multicolumn{2}{|l|}{$\mathrm{m} 6 \mathrm{~A}$} & \multicolumn{2}{|c|}{ Total number (involved genes } \\
\hline & & & & & & C6706 & $\mathrm{CV} 2$ & C6706 & $\mathrm{CV} 2$ & C6706 & $\mathrm{CV} 2$ \\
\hline \multirow[t]{3}{*}{ | } & VC & 2775 & 80,978 & 36,609 & $117,587(2744)$ & 61,330 & 56,919 & 2203 & 1882 & $63,533(2715)$ & $58,801(2700)$ \\
\hline & $V C_{-} r$ & 25 & 1697 & 419 & $2116(25)$ & 1093 & 1082 & 56 & 94 & 1149 [23] & $1176(24)$ \\
\hline & $V C_{-} t$ & 94 & 314 & 70 & $384(85)$ & 236 & 231 & 12 & 6 & $248(79)$ & $237(82)$ \\
\hline \multirow[t]{2}{*}{$\|$} & VC_A & 1115 & 2980 & 1501 & $4481(486)$ & 2476 & 2335 & 137 & 105 & $2613(464)$ & $2440(447)$ \\
\hline & VC_At & 4 & 3 & 0 & $3(1)$ & 2 & 3 & 0 & 0 & $2(1)$ & $3(1)$ \\
\hline Total & & 4013 & 85,972 & 38,599 & $124,571(3341)$ & 65,137 & 60,570 & 2408 & 2087 & $67,545(3282)$ & $62,657(3254)$ \\
\hline
\end{tabular}

\section{${ }^{\mathrm{m} 5} \mathrm{C}$ methylation in bisulfite sequencing}

Because of the failure of ${ }^{\mathrm{m} 5} \mathrm{C}$ site detection in SMRT, we had to use the traditional ${ }^{\mathrm{m} 5} \mathrm{C}$ analysis method, bisulfite sequencing. Samples C6706 and CV2 produced 16,196, $082 \mathrm{bp}$ and 16,232,236 bp clean reads, respectively. The mapping rates were 96.01 and $91.78 \%$; the bisulfite conversion rates were 99.65 and $99.62 \%$; and the average depths were $362.12 x$ and $345.69 x$, respectively. We detected 6965 methylcytosines in C6706 and 7321 methylcytosines in CV2 from a total of 1,915,376 cytosines in the $V$. cholerae genome. This increase in the number of methylcytosines in CV2 was consistent with the increase in untyped methylation sites in SMRT sequencing and the cytosine-specificity of the MTases on the IncA/ $C_{2}$ plasmid. The average methylation levels of the three types of $\mathrm{C}$ bases (mCG, $\mathrm{mCHG}$ and $\mathrm{mCHH}$, where $\mathrm{H}=\mathrm{A}, \mathrm{C}$ or $\mathrm{T}$ ) were higher in $\mathrm{CV} 2$ than in C6706. At the whole-genome level, the $\mathrm{mCG}, \mathrm{mCHG}$ and $\mathrm{mCHH}$ methylation levels

Table 4 Motifs in C6706 and CV2 as determined by SMRT sequencing

\begin{tabular}{|c|c|c|c|c|c|c|c|c|c|c|c|}
\hline \multirow[t]{2}{*}{ Types } & \multirow[t]{2}{*}{ Motif } & \multicolumn{2}{|c|}{$\mathrm{nGenome}^{\mathrm{a}}$} & \multicolumn{2}{|l|}{${ }^{\mathrm{m} 6} \mathrm{~A}$} & \multicolumn{2}{|l|}{${ }^{\mathrm{m} 4} \mathrm{C}$} & \multicolumn{2}{|c|}{ Modified_base } & \multicolumn{2}{|c|}{$\begin{array}{l}\text { Undetected } \\
\text { modification sites }\end{array}$} \\
\hline & & C6707 & $\mathrm{CV} 2$ & C6707 & $\mathrm{CV} 2$ & C6707 & $\mathrm{CV} 2$ & C6707 & $\mathrm{CV} 2$ & C6707 & $\mathrm{CV} 2$ \\
\hline \multirow{6}{*}{$\begin{array}{l}\text { Common } \\
\text { (6 types) }\end{array}$} & AAGNNNNNNCATC & 454 & 532 & 452 (99.6\%) & $528(99.2 \%)$ & 0 & 0 & $1(0.2 \%)$ & 0 & $1(0.2 \%)$ & $4(0.8 \%)$ \\
\hline & AKDTRGCA & 386 & 476 & 181 (46.9\%) & $244(51.3 \%)$ & 0 & 0 & $168(43.5 \%)$ & $186(39.1 \%)$ & 37 (9.6\%) & $46(9.7 \%)$ \\
\hline & AKGYANYA & 755 & 456 & 300 (39.7\%) & $171(37.5 \%)$ & 0 & 0 & $260(34.4 \%)$ & 93 (20.4\%) & 195 (25.8\%) & $192(42.1 \%)$ \\
\hline & GATC & 37,401 & 34,375 & $\begin{array}{l}37,070 \\
(99.1 \%)\end{array}$ & $\begin{array}{l}33,991 \\
(98.9 \%)\end{array}$ & 0 & 0 & $71(0.2 \%)$ & $95(0.3 \%)$ & $260(0.7 \%)$ & $289(0.8 \%)$ \\
\hline & GATGNNNNNNCTT & 613 & 562 & 609 (99.3\%) & $558(99.3 \%)$ & 0 & 0 & $4(0.7 \%)$ & $3(0.5 \%)$ & 0 & $1(0.2 \%)$ \\
\hline & TNNNNNNH & 348,498 & 334,917 & 0 & 0 & 0 & 0 & $\begin{array}{l}220,207 \\
(63.2 \%)\end{array}$ & $\begin{array}{l}213,464 \\
(63.7 \%)\end{array}$ & $\begin{array}{l}128,291 \\
(36.8 \%)\end{array}$ & $\begin{array}{l}121,453 \\
(36.3 \%)\end{array}$ \\
\hline \multirow[t]{5}{*}{$\begin{array}{l}\text { C6707 specific } \\
\text { ( } 5 \text { types) }\end{array}$} & AGKNNNNW & 5445 & 0 & $\begin{array}{l}2795 \\
(51.33 \%)\end{array}$ & 0 & 0 & 0 & $\begin{array}{l}1727 \\
(31.7 \%)\end{array}$ & 0 & $923(17.0 \%)$ & 0 \\
\hline & GADNDGCG & 2993 & 0 & 0 & 0 & 0 & 0 & $\begin{array}{l}1403 \\
(46.9 \%)\end{array}$ & 0 & $\begin{array}{l}1590 \\
(53.1 \%)\end{array}$ & 0 \\
\hline & GARVNNDG & 13,031 & 0 & 0 & 0 & 0 & 0 & $\begin{array}{l}8830 \\
(67.8 \%)\end{array}$ & 0 & $\begin{array}{l}4201 \\
(32.2 \%)\end{array}$ & 0 \\
\hline & TWNNNDG & 26,727 & 0 & 0 & 0 & 0 & 0 & $\begin{array}{l}15,684 \\
(58.7 \%)\end{array}$ & 0 & $\begin{array}{l}11,043 \\
(41.3 \%)\end{array}$ & 0 \\
\hline & DCAGVHRNG & 1490 & 0 & 0 & 0 & $\begin{array}{l}476 \\
(31.9 \%)\end{array}$ & 0 & 665 (44.6\%) & 0 & $349(23.4 \%)$ & 0 \\
\hline \multirow[t]{4}{*}{$\begin{array}{l}\text { CV2 specific } \\
\text { (4 types) }\end{array}$} & ABNBMVBW & 0 & 10,259 & 0 & $\begin{array}{l}6318 \\
(61.8 \%)\end{array}$ & 0 & 0 & 0 & $\begin{array}{l}2596 \\
(25.3 \%)\end{array}$ & 0 & $\begin{array}{l}1345 \\
(13.1 \%)\end{array}$ \\
\hline & GANNDBBG & 0 & 14,158 & 0 & 0 & 0 & 0 & 0 & $\begin{array}{l}8130 \\
(57.4 \%)\end{array}$ & 0 & $\begin{array}{l}6028 \\
(42.6 \%)\end{array}$ \\
\hline & GARVNRNG & 0 & 7699 & 0 & 0 & 0 & 0 & 0 & $\begin{array}{l}4448 \\
(57.8 \%)\end{array}$ & 0 & $\begin{array}{l}3251 \\
(42.2 \%)\end{array}$ \\
\hline & TNWNNDG & 0 & 27,441 & 0 & 0 & 0 & 0 & 0 & $\begin{array}{l}16,388 \\
(59.7 \%)\end{array}$ & 0 & $\begin{array}{l}11,053 \\
(40.3 \%)\end{array}$ \\
\hline
\end{tabular}

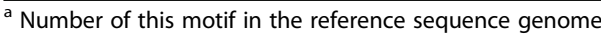


were $0.33,1.74$ and $0.43 \%$ in C6706, respectively, and 0.34 , 1.81 and $0.44 \%$ in CV2, respectively. Moreover, the graphs of the methylation levels also showed a slight increasing trend from C6706 to CV2 (Fig. 1A). For example, 50\% of the $\mathrm{mCHH}$ sites were $10 \%$ methylated in C6706; it were $59 \%$ of the $\mathrm{mCHH}$ sites $20 \%$ methylated in CV2. Notably, although the total number of $\mathrm{mCG}$ sites was the most similar between C6706 and CV2, the methylation levels of these sites were greatly different. The methylation levels of the mCG sites changed as follows: $68 \%$ of the mCG sites were $10 \%$ methylated and $32 \%$ of the mCG sites were 20\% methylated in C6706; 19\% of the mCG sites were $10 \%$ methylated, $57 \%$ of the mCG sites were $20 \%$ methylated, and $18 \%$ of the mCG sites were $30 \%$ methylated in CV2 (Fig. 1a).

The global-scale view of the DNA methylation density in 100-kb windows (Fig. 1b) revealed that there was no correlation between the distributions of the three methylation types on the two chromosomes of $V$. cholerae. The density of mCG methylation was relatively steady in each chromosomal region, while the non-CG methylation levels fluctuated greatly throughout each chromosome. In C6706 and $\mathrm{CV} 2$, the smooth profiles of the mCHG density remained constant, but the $\mathrm{mCHH}$ density profiles changed dramatically without any similarity (Fig. 1b).

The sequence characteristics of the bases in the vicinity of a methylation site reflect the preference of MTases for recognition of specific sequences, so we calculated the methylation percentage of the nine bases upstream and downstream of the methylation site ( $\mathrm{mC}$ at the fourth base) . The enrichment of particular local sequences was observed for both mCG and non-CG methylcytosine (Additional file 2: Figure S1). 5'-RCCGGY-3' was the recognition sequence of $\mathrm{mCHG}$, and preferences for an $\mathrm{AG}$ dinucleotide of $\mathrm{mCG}$ and a $\mathrm{C}$ of $\mathrm{mCHH}$ upstream of the methylation sites were observed. This result was consistent with the analysis of $v c h M$ [11], but also showed that in addition to the 5'-RCCGGY-3' sequence, although the 5'CCWGG-3' sites were unmethylated, other ${ }^{\mathrm{m} 5} \mathrm{C}$ methylated sequences existed in V. cholerae. C6706 and CV2 were identical in this sequence preference, but there were differences in the relative frequency of the bases before and after the recognition sites of $\mathrm{mCG}$ and $\mathrm{mCHH}$ (Fig. 1c).

In C6706, $6833{ }^{\mathrm{m} 5} \mathrm{C}$ methylation sites were located in 1436 genes on chromosome I and in 446 genes on chromosome II, accounting for 49.60 and $39.85 \%$ of the total genes of the two chromosomes, respectively, and included $459{ }^{\mathrm{m} 5} \mathrm{C}$ sites in intergenic regions. In CV2, 6851 ${ }^{\mathrm{m} 5} \mathrm{C}$ methylation sites were located in 1554 genes on chromosome I, 492 genes on chromosome II, and 471 sites in intergenic regions. Between the two samples, $6466{ }^{\mathrm{m} 5} \mathrm{C}$ methylation sites remained constant. There were 499 differential ${ }^{\mathrm{m} 5} \mathrm{C}$ sites in $\mathrm{C} 6706$ and 856 sites in CV2, involving 377 and 635 genes, respectively. There were almost no identical $\mathrm{mCHH}$ methylation sites between $\mathrm{C6706}$ and CV2, similar to the mCG sites on chromosome II of the two strains (Table 5). Overall, DNA methylation in nonCG contexts (mCHG and $\mathrm{mCHH}$ ) accounted for an absolute majority (99.87 and 99.78\%) in $V$. cholerae and accounted for most of the differences in methylation before and after plasmid transformation.

\section{Methylation of host MTase genes}

Four of the six MTase genes on the $V$. cholerae chromosomes had ${ }^{\mathrm{m} 4} \mathrm{C}$ and ${ }^{\mathrm{m} 6} \mathrm{~A}$ methylated sites; VC1769 was the only gene that had all three methylation types. We did not detect any typed methylation sites on VCA0627 or on the orphan Dcm gene, VCA0158 (Table 6). After transformation with pVC211, only a few ${ }^{\mathrm{m} 6} \mathrm{~A}$ sites changed, while more than half of the ${ }^{\mathrm{m} 4} \mathrm{C}$ sites changed. Therefore, it was reasonable to observe the large-scale change in the methylation profile of the host chromosomes by SMRT sequencing. Combined with changes in ${ }^{\mathrm{m} 5} \mathrm{C}$ sites determined by bisulfite sequencing, our results suggested that changes in the host methylation profile were partly attributable to the indirect role of host MTases that were affected by the plasmid and were partly attributable to the direct role of plasmid-encoded MTases themselves.

\section{Knockouts of the three MTase genes on pVC211}

All seven types of VC211 mutants, including single, two and three $\mathrm{dcm}$ gene deletions, were constructed successfully, which indicated that none of the three methylase genes were essential for pVC211. However, among the secondary homologous recombinants selected from the sucrose plates to test for the gene deletion, several clones lost pVC211, except for the wild-type strains and the target gene-deleted strains. These clones were positive for amplification with the $\operatorname{ctx} A B-\mathrm{U} / \mathrm{L}$ primer set and negative for the del $d c m 1 / 4$ and repA-F/R primer sets. To confirm this phenomenon, all seven types of gene knockouts were repeated twice. The highest plasmid loss rate was found in the $d c m 1$ single-gene deletion, with an average of 37/96 (the wild-type rate was $14 / 96$, and the gene deletion rate was 45/96). Among the other five types of deletions, the plasmid loss rate was approximately 18/96, while plasmid loss was not observed in the $d c m 2$ single-gene deletion. Accompanied with the loss of this IncA/C plasmid, the $V$. cholerae strain $\mathrm{VC} 211$ changed from a strain with erythromycin (MIC>128 $\mu \mathrm{g} / \mathrm{ml})$, azithromycin $(\mathrm{MIC} \geq 64 \mu \mathrm{g} / \mathrm{ml})$ and tetracycline $(16 \mu \mathrm{g} / \mathrm{ml})$ resistance [6] to a sensitive strain.

The loss of pVC211 in the deletion process of the $\mathrm{dcm}$ genes indicated that the $d c m$ genes might affect the plasmid stability, so the presence of plasmids was detected by PCR in the 96 clones of the VC211 $\Delta d c m 1$ and $\mathrm{VC} 211 \Delta(\mathrm{dcm} 1, \mathrm{dcm} 2, d \mathrm{~cm} 3)$ mutant strains after three continuous passage cultures in $5 \mathrm{ml}$ Luria-Bertani (LB) 

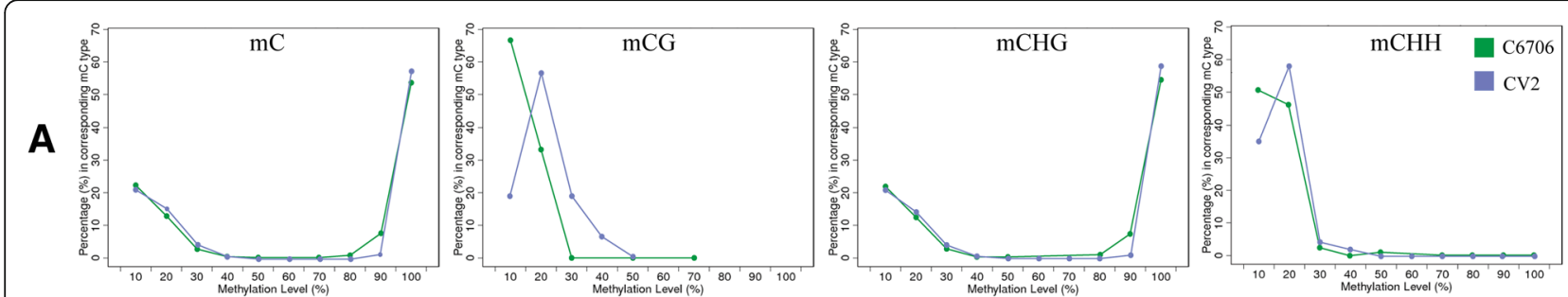

$\mathrm{mCG} / \mathrm{CG}$
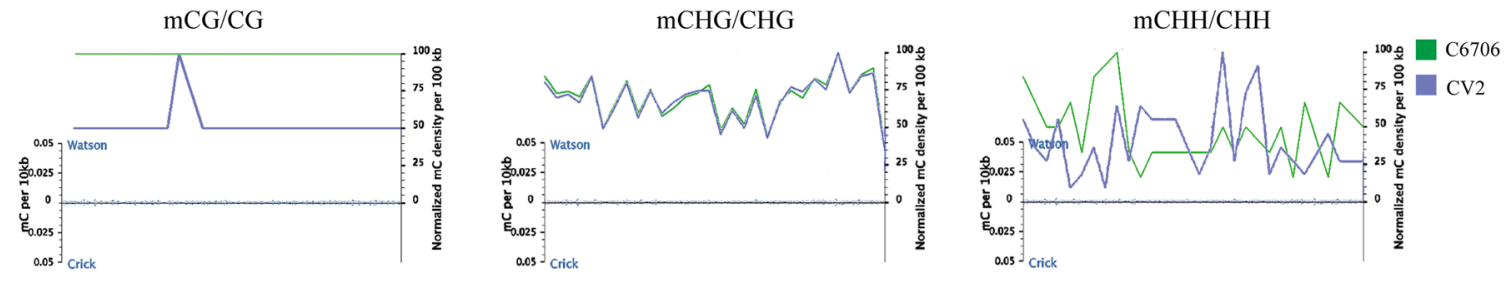

B
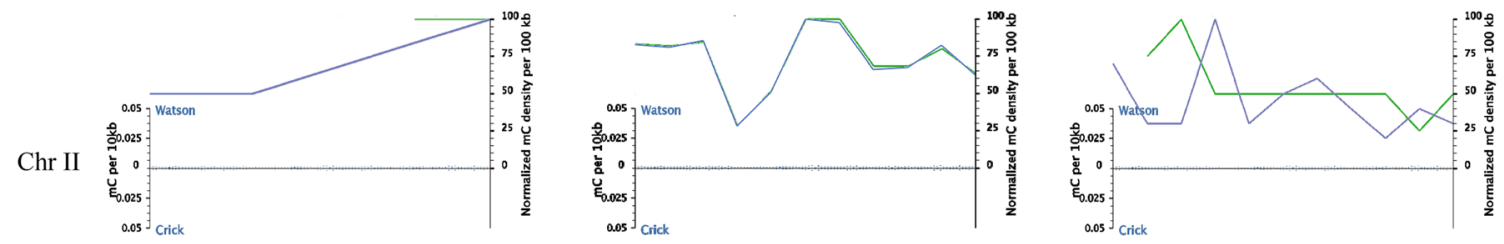

$\mathrm{mCG}$
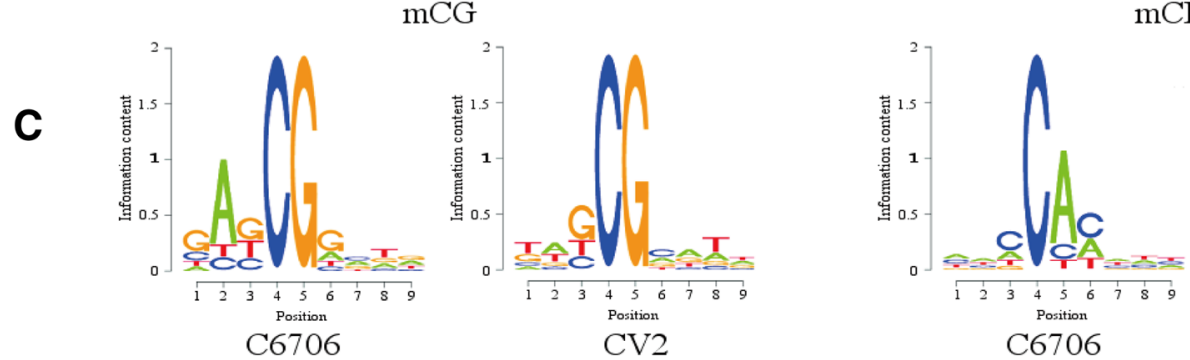

$\mathrm{mCHH}$

Fig. 1 Global trends of the methylomes of C6706 and CV2 and logo plots of the non-CG methylation patterns. A. Distribution of the methylation level in the C6706 and CV2 samples. The x-axis indicates the methylation level, and the $y$-axis indicates the fraction of $\mathrm{mC}$ at a specific methylation level in all methylcytosines. The methylation level of cytosine is the proportional value of the sequence supporting the $\mathrm{C}$ base site as a methylation site in the effective coverage sequence. B. The density distribution of $\mathrm{mC}$ on each chromosome. The $\mathrm{x}$-axis represents the chromosome. The $\mathrm{y}$-axis on the left represents the $\mathrm{mC}$ density calculated from a $10 \mathrm{~kb}$ window, and the blue dot represents the distribution of the $\mathrm{mC}$ density on the chromosome. The $\mathrm{y}$-axis on the right represents the normalized $\mathrm{mC}$ ratio. The curves represent the density distribution of the different types of $\mathrm{mC}$ bases ( $\mathrm{CG}, \mathrm{CHG}$ and $\mathrm{CHH}$ ). C. Logo plots of the sequence features of the adjacent bases at the $\mathrm{C}$ site. The $\mathrm{x}$-axis represents the base position, with the C-base being analyzed in the fourth position. The $y$-axis represents the entropy value

Table 5 Three methylation types of C bases in bisulfite sequencing between C6706 and CV2

\begin{tabular}{|c|c|c|c|c|c|c|c|c|c|c|}
\hline \multirow[t]{3}{*}{ Chromosome } & \multirow[t]{3}{*}{ Location } & \multicolumn{3}{|c|}{ Constant } & \multicolumn{6}{|c|}{ Differential } \\
\hline & & \multirow[t]{2}{*}{$\mathrm{mCG}$} & \multirow[t]{2}{*}{$\mathrm{mCHG}$} & \multirow[t]{2}{*}{$\mathrm{mCHH}$} & \multicolumn{2}{|l|}{$\overline{\mathrm{mCG}}$} & \multicolumn{2}{|l|}{$\mathrm{mCHG}$} & \multicolumn{2}{|l|}{$\mathrm{mCHH}$} \\
\hline & & & & & C6706 & $\mathrm{CV} 2$ & C6706 & $\mathrm{CV} 2$ & C6706 & $\mathrm{CV} 2$ \\
\hline \multirow[t]{2}{*}{ I } & gene & 3 & 4674 & 1 & 2 & 4 & 269 & 458 & 54 & 110 \\
\hline & intergenic & 1 & 263 & 0 & 2 & 3 & 37 & 30 & 15 & 18 \\
\hline \multirow[t]{3}{*}{$\|$} & gene & 0 & 1400 & 0 & 4 & 3 & 76 & 159 & 23 & 39 \\
\hline & intergenic & 0 & 124 & 0 & 1 & 2 & 10 & 19 & 6 & 11 \\
\hline & total & 4 & 6461 & 1 & 9 & 12 & 392 & 666 & 98 & 178 \\
\hline
\end{tabular}


Table 6 Methylation of the six host MTase genes

\begin{tabular}{|c|c|c|c|c|c|c|c|c|c|c|}
\hline \multirow[t]{3}{*}{ MTase } & \multirow[t]{3}{*}{ Gene } & \multicolumn{3}{|l|}{${ }^{\mathrm{m} 4} \mathrm{C}$} & \multicolumn{3}{|l|}{${ }^{\mathrm{m} 6} \mathrm{~A}$} & \multicolumn{3}{|l|}{${ }^{\mathrm{m} 5} \mathrm{C}$} \\
\hline & & \multirow[t]{2}{*}{ Constant } & \multicolumn{2}{|c|}{ Differential } & \multirow[t]{2}{*}{ Constant } & \multicolumn{2}{|c|}{ Differential } & \multirow[t]{2}{*}{ Constant } & \multicolumn{2}{|c|}{ Differential } \\
\hline & & & $\mathrm{C}$ & $\mathrm{CV} 2$ & & $\mathrm{C}$ & CV2 & & $\bar{C}$ & $\mathrm{CV} 2$ \\
\hline \multirow[t]{3}{*}{ Dam } & VC1769 & 39 & 29 & 44 & 22 & 3 & 6 & 2 & 0 & 0 \\
\hline & VC2118 & 19 & 25 & 19 & 16 & 0 & 1 & - & - & - \\
\hline & VC2626 & 16 & 40 & 22 & 9 & 0 & 0 & - & - & - \\
\hline \multirow[t]{2}{*}{ rRNA MTase } & VC2697 & 18 & 42 & 19 & 17 & 0 & 1 & - & - & - \\
\hline & VCA0627 & - & - & - & - & - & - & - & - & - \\
\hline Dem (vchM) & VCA0158 & - & - & - & - & - & - & - & - & - \\
\hline
\end{tabular}

broth without any antibiotics; PCR was performed with the $\operatorname{rep} A-\mathrm{F} / \mathrm{R}$ primer set as described previously [7]. None of the progeny clones that lost the plasmid were detected, and the results show that the IncA/C plasmids with the three $\mathrm{dcm}$ genes deleted continued to exist stably in host $V$. cholerae strains.

The transferability of pVC211 $(d c m 1, d c m 2, d c m 3)$ between the $V$. cholerae strains was tested. VC $211 \Delta(d c m 1$, $d c m 2, d c m 3)$ was conjugated with N16961 (lacZ::kan ${ }^{\mathrm{r}}$ ), C6706 (lacZ:: $\operatorname{kan}^{\mathrm{r}}$ ), VC2981 and VC2973 and then spread onto LB plates containing two antibiotics using VC211 as a control. The results show that the pVC211 plasmid lacking the three $\mathrm{dcm}$ genes could no longer be transferred to other $V$. cholerae strains. Furthermore, freshly cultured SM10 strains were divided into two aliquots and conjugated with $\mathrm{VC} 211 \Delta(d c m 1, d c m 2, d c m 3)$ and $\mathrm{VC} 211$ to test the plasmid transferability between the $V$. cholerae and $E$. coli strains. The results were interesting. The clones grown on the double antibiotics LB plates of the SM10 and VC211 conjugation were positive for repA-F/R amplification and negative for $\operatorname{ctx} A B-\mathrm{U} / \mathrm{L}$ amplification, indicating that the pVC211 plasmid had been transferred into SM10. All of the clones grown on the plates of the conjugation of SM10 and $\mathrm{VC} 211 \Delta(d c m 1, d c m 2, d c m 3)$ were positive for $r e p A-\mathrm{F} / \mathrm{R}$ and $c t x A B-\mathrm{U} / \mathrm{L}$ amplification. These clones were also positive for the kan-mini-U/L amplification of mini-Tn5 and were resistant to kanamycin (100 $\mu \mathrm{g} / \mathrm{mL})$, indicating that instead of $\mathrm{pVC} 211 \Delta(\mathrm{dcm} 1, \mathrm{dcm} 2$, $d c m 3)$ being transferred into SM10, the mini-Tn5 transposon of SM10 [17] was transferred into V. cholerae.

\section{Discussion}

Methylation plays important roles in epigenetic gene regulation in both eukaryotic and prokaryotic organisms. Compared with the explicit function of Dam methylation in mismatch repair, initiation of chromosome replication, transcription regulation at promoters containing GATC sequences, gene expression, pathogenicity and DNA stability under antibiotic pressure [18], knowledge of the function of Dcm MTase is limited [2]. The original function elucidated for Dcm was to discriminate self DNA from foreign
DNA as part of the RM system [19] and to affect the plasmid transfer efficiency and dissemination of antibiotic resistance genes in Enterococcus faecalis [15]. Therefore, the discovery that two of the three MTase genes on the IncA/ $\mathrm{C}_{2}$ plasmid are cytosine-specific was intriguing.

Three types of methylation, namely, ${ }^{\mathrm{m} 6} \mathrm{~A},{ }^{\mathrm{m} 4} \mathrm{C}$ and ${ }^{\mathrm{m} 5} \mathrm{C}$, and a large amount of methylation without obvious methylation patterns exist in $V$. cholerae. Comparison of the genome-wide methylation profiles of $V$. cholerae C6706 before and after the conjugation of pVC211 revealed that the MTases of the IncA/C plasmid changed the number and characteristics of all types of methylation. The changes involved most of the regions of the two chromosomes, and no obvious preference for gene function was observed. It seemed that the host chromosomes were completely relabeled by the plasmid with a methylation pattern different from that of the host itself. Surprisingly, the new methylation pattern induced by the plasmid could be tolerated by the restriction enzymes of the host's RM system.

After loss of the three $d c m$ genes, pVC211 could not be transferred into other $V$. cholerae and $E$. coli strains as the wild-type plasmid, which demonstrated that instead of mimicking the host's methylation pattern [20], pVC211 crossed the barrier of the host's RM system by actively changing the host's methylation pattern. This is the simplest and most general method by which IncA/C plasmids obtain their broad host range. Although pVC211 $\Delta(d c m 1, d c m 2, d c m 3)$ could no longer be transferred, this plasmid could still stably exist in the host strain when there was no selection pressure. We speculated that once the plasmid entered the host, other genes on the plasmid participated in plasmid maintenance, and methylation was no longer the only determinant of plasmid stability. After deletion of the $\mathrm{dcm}$ genes, the mini-Tn5 transposon of SM10 could enter VC211. Combined with the methylation of the host chromosomes by the plasmid, this finding suggested that the MTases of the plasmid actually constructed a new RM barrier to nonself DNA for itself. In addition to the bacterial RM for foreign DNA on chromosomes, the mobile genetic elements could also carry 
their own barriers. Moreover, transfer of the suicide plasmid pWM91 into VC211 clearly demonstrated the selectivity of the IncA/C RM barrier.

In addition, it is worth noting the loss of the IncA/C plasmid during the deletion of the $d \mathrm{~cm}$ genes. In theory, after the first recombination, the suicide plasmid pWM91 was inserted into pVC211, and it was possible that the pVC211 plasmid was expelled with pWM91 due to the toxic effect of the $s a c B$ gene on the sucrose plate. However, IncA/C plasmids were very stable in $V$. cholerae [7], and in the previous deletions of plasmid genes [6], only the secondary recombined wild-type strains and the gene deletion strains were obtained after sucrose selection. The loss of the IncA/C plasmid together with the suicide plasmid never occurred as it did in the deletion of the $d c m 2$ gene in this study. Therefore, even the $\mathrm{dcm}$ genes were not the determinants of plasmid stability, and after the deletion of the $\mathrm{dcm}$ genes, the plasmids continued to exist stably in the subcultures, the loss of plasmid caused by the $\mathrm{dcm}$ gene deletion indicated that these genes could possibly contribute to the stability of the plasmids. Loss of the IncA/C plasmids transformed the host bacteria from plasmid-conferred antibiotic resistant strains to sensitive strains. This result indicated that elimination of plasmids by destruction of plasmid stability could be a new, effective strategy to address bacterial multidrug resistance.

\section{Conclusions}

MTases of the IncA/C plasmid were a mobile RM system of plasmids against nonself DNA, including host chromosomes and other mobile genetic elements. By actively changing the host's methylation pattern, this system helped the plasmids cross the barrier of the host's RM system and enabled the broad host range of the plasmids.

\section{Materials and methods Strains and plasmids}

The toxigenic O1 El Tor strain C6706 and N16961 are commonly used $V$. cholerae reference strains, isolated in 1991 from Peru [21] and 1971 from Bangladesh, respectively [22]. VC2981 and VC2973 are nontoxigenic O1 El Tor strains with ampicillin resistance isolated from Jiangsu Province in 1965 . The IncA/ $C_{2}$ plasmid pVC211 was identified in a toxigenic O139 serogroup strain VC211 isolated in 2003 from Guangdong Province, China [6].

\section{Construction of the kanamycin-resistant mutants of C6706 and N16961}

The kanamycin resistance gene was amplified from the plasmid pet-ken with the kan-844-stuI-U/L primer set and was digested with the enzyme stuI; then, this gene was ligated to the vector $\mathrm{pJL}-1$, which was also digested with stuI, and transformed into the Escherichia coli strain SM10. By conjugation and via the homologous arms of the lac $Z$ genes on pJL-1, a kanamycin (kan) resistance gene was inserted into the genomes of the $V$. cholerae strains N16961 (streptomycin, str ${ }^{\mathrm{r}}$ ) and C6706 $\left(\operatorname{str}^{\mathrm{r}}\right)$. Then, N16961 (lacZ::kan $\left.{ }^{\mathrm{r}}, \operatorname{str}^{\mathrm{r}}\right)$ and C6706 (lacZ:: $\left.\operatorname{kan}^{\mathrm{r}}, \operatorname{str}^{\mathrm{r}}\right)$ were constructed. Furthermore, the pVC211 plasmid was transferred into C6706 (lacZ:: $\operatorname{kan}^{\mathrm{r}}$, $\operatorname{str}^{\mathrm{r}}$ ) by conjugation, and the strain $\mathrm{CV} 2$ was constructed.

\section{Bisulfite sequencing}

Genomic DNA was fragmented into 250-bp fragments using Bioruptor (Diagenode, Belgium). The fragments were blunt ended, phosphorylated, subjected to 3 '-dA overhang generation and ligated to methylated sequencing adaptors. Then, the samples were treated with bisulfite by using the EZ DNA Methylation-Gold Kit (Zymo Research, Inc., Irvine, CA, USA), desalted and size selected by $2 \%$ agarose gel electrophoresis. After PCR amplification and another round of size selection, the qualified libraries were sequenced. The sequencing data were filtered, and the low-quality data were removed. Then, the clean data were mapped onto the reference genome (the complete genome sequences of the standard strain N16961, AE003852 and AE00 3853; BSMAP) to obtain the methylation information for all cytosines throughout the genome for standard and personalized bioinformatic analysis. The average methylation level was calculated as follows:

$$
\mathrm{Rm}_{\text {average }}=\frac{\mathrm{Nm}_{\text {all }}}{\mathrm{Nm}_{\text {all }}+\mathrm{Nnm}_{\text {all }}} \times 100 \%
$$

where $\mathrm{Nm}$ is the number of methylated cytosines, and $\mathrm{Nnm}$ is the number of reads with nonmethylated cytosines. Windows containing at least 5 CG (CHG or $\mathrm{CHH}$ ) at the same location in the two genomes were identified, and the difference in the level of CG methylation in these windows between the two samples was compared to find regions with significant differences in methylation (differentially methylated region, DMR; 2-fold difference, Fisher test $P$ value $\leq 0.05$ ). If two adjacent DMRs formed a contiguous region with significantly different methylation levels in both samples, the two DMRs were merged into one continuous DMR; otherwise, these DMRs were considered to be separate.

CIRCOS was used to compare the differences in the methylation levels of DMRs between the samples. The degree of difference in the methylation level at one site in the two samples was calculated by the following formula, where $\mathrm{Rm} 1$ and $\mathrm{Rm} 2$ represent the $\mathrm{mC}$ methylation level of the two samples. If the value of 
either $R m 1$ or $R m 2$ was 0 , it was replaced with 0.001 [23].

$$
\text { Degree of difference }=\frac{\log _{2} R m 1}{\log _{2} R m 2}
$$

\section{SMRT sequencing}

First, the target fragments were amplified from the qualified DNA samples by PCR. Then, the damaged ends of the fragments were repaired. Both sides of the DNA fragments were connected with a hairpin adapter to obtain a dumbbell (set of horse ring) structure, which is known as SMRTbell. After annealing, the SMRTbell was fixed at the bottom of the ZWM polymerase and used for sequencing. SMRT sequencing was carried out on PacBio RS II instrument (Pacific Biosciences; Menlo Park, CA, USA) using standard protocols. The polymerase reads with lengths less than $50 \mathrm{bp}$ or mass values less than 0.75 were filtered out. Then, the clean data were mapped to the reference genome (AE003852 and AE003853) using the P_Mapping Module of SMRT Analysis software (v2.3.0). The P_Modification Detection (score $\geq 20$, coverage $\geq 25$ and identificationQ $\mathrm{v} \geq 20$ ) and P_MotifFind (score $\geq 20$ and coverage $\geq 25$ ) Modules were used to identify the methylation sites and motifs. All kinetic raw data from SMRT sequencing have been deposited in NCBI (SRA, PRJNA477395).

\section{Construction of the gene deletion mutants}

To construct the dcm $1, d c m 2$ and $d c m 3$ gene deletion mutants of strain VC211, two-step overlap PCR was used to generate the fused homologous arms of the target genes. For example, the flanking regions upstream and downstream of $d c m 1$ were amplified from the genomic DNA of VC211 with two primer sets: del-dcm1-1-SacI and del-dcm1-2, and del-dcm1-3 and del-dcm1-4-SpeI. After gel purification, the PCR products were mixed, diluted 1000-fold and used as templates for the second round of PCR with the 1 and 4 primers of each gene (primers used in the study are listed in Additional file 3: Table S1). Then, the overlap PCR products and suicide plasmid pWM91were double digested with SacI and SpeI and were ligated and transformed into SM10. By conjugation and negative selection with $10 \%$ sucrose, the $d c m 1$, $d c m 2$ and dcm 3 deletion mutants of VC211 were constructed. Ninety-eight clones on the sucrose plates of each deletion were selected and tested by PCR with the del $d c m 1$ and 4 primers of each gene; these clones were further verified by the $d c m$-test-U/L primer sets. The presence of the IncA/C plasmid in the strains was also confirmed by the primer set repA-F/R for the plasmid replicase [7], and the primer set $c t x A B-\mathrm{U} / \mathrm{L}$ for the toxic gene $\operatorname{ctx} A B$ of $V$. cholerae was used as a positive control. On the basis of single-gene deletion, the two-gene deletion mutants $\mathrm{VC} 211 \Delta(d c m 1, d c m 2), \mathrm{VC} 211 \Delta(d c m 2, d c m 3)$, and $\mathrm{VC} 211 \Delta(\mathrm{dcm} 1, \mathrm{dcm} 3)$ and the three-gene deletion mutant $\operatorname{VC} 211 \Delta(d c m 1, d c m 2, d c m 3)$ were constructed by the same method.

\section{Additional files}

Additional file 1: Table S2. Genes with obviously changed methylation type in SMRT sequencing. (PDF $77 \mathrm{~kb}$ )

Additional file 2: Figure S1. The methylation percentage of the 9 bases flanking the methylation site of ( $\mathrm{mC}$ at the fourth base). (PDF $89 \mathrm{~kb}$ )

Additional file 3: Table S1. Primers used in this study. (PDF 8 kb)

\section{Abbreviations}

DMR: Differentially methylated region; LB: Luria-Bertani; RM: Restriction modification; SMRT: Single-molecule, real-time

\section{Author contributions}

R.W. designed the project, analyzed and interpreted the data, prepared the figures and wrote the manuscript; Jing Lou and Jie Li cultured and stored the strains.

\section{Funding}

This work was supported by grants from the State Key Laboratory of Pathogen and Biosecurity (Academy of Military Medical Science) (SKLPBS1521).

Availability of data and materials

All the data supporting the findings are presented in the manuscript and the associated supplementary information file. The raw data were deposited into NCBI (SRA, PRJNA477395).

Ethics approval and consent to participate

Not applicable.

Consent for publication

Not applicable.

\section{Competing interests}

The authors declare no competing interests.

Received: 27 February 2019 Accepted: 31 May 2019

Published online: 07 June 2019

References

1. Fricke WF, Welch TJ, McDermott PF, Mammel MK, LeClerc JE, White DG, et al. Comparative genomics of the IncA/C multidrug resistance plasmid family. J Bacteriol. 2009;191(15):4750-7 Epub 2009/06/02.

2. Harmer CJ, Hall RM. The a to Z of a/C plasmids. Plasmid. 2015;80:63-82 Epub 2015/04/26.

3. Welch TJ, Fricke WF, McDermott PF, White DG, Rosso ML, Rasko DA, et al. Multiple antimicrobial resistance in plague: an emerging public health risk. PLoS One. 2007;2(3):e309 Epub 2007/03/22.

4. Giske CG, Froding I, Hasan CM, Turlej-Rogacka A, Toleman M, Livermore D, et al. Diverse sequence types of Klebsiella pneumoniae contribute to the dissemination of blaNDM-1 in India, Sweden, and the United Kingdom. Antimicrob Agents Chemother. 2012;56(5):2735-8 Epub 2012/02/23.

5. Hsueh PR. New Delhi metallo-ss-lactamase-1 (NDM-1): an emerging threat among Enterobacteriaceae. J Formos Med Assoc. 2010;109(10):685-7 Epub 2010/11/03.

6. Wang R, Liu H, Zhao X, Li J, Wan K. InCA/C plasmids conferring high azithromycin resistance in Vibrio cholerae. Int J Antimicrob Agents. 2018; 51(1):140-4 Epub 2017/09/19.

7. Wang R, Yu D, Zhu L, Li J, Yue J, Kan B. IncA/C plasmids harboured in serious multidrug-resistant Vibrio cholerae serogroup 0139 strains in China. Int J Antimicrob Agents. 2015;45(3):249-54 Epub 2014/12/24.

8. Doublet B, Boyd D, Douard G, Praud K, Cloeckaert A, Mulvey MR. Complete nucleotide sequence of the multidrug resistance IncA/C plasmid pR55 from 
Klebsiella pneumoniae isolated in 1969. J Antimicrob Chemother. 2012; 67(10):2354-60. Epub 2012/07/10.

9. Glenn LM, Englen MD, Lindsey RL, Frank JF, Turpin JE, Berrang ME, et al. Analysis of antimicrobial resistance genes detected in multiple-drugresistant Escherichia coli isolates from broiler chicken carcasses. Microb Drug Resis. 2012;18(4):453-63 Epub 2012/03/06.

10. Fernandez-Alarcon C, Singer RS, Johnson TJ. Comparative genomics of multidrug resistance-encoding IncA/C plasmids from commensal and pathogenic Escherichia coli from multiple animal sources. PLoS One. 2011; 6(8):e23415 Epub 2011/08/23.

11. Banerjee S, Chowdhury R. An orphan DNA (cytosine-5-)-methyltransferase in Vibrio cholerae. Microbiology. 2006;152(Pt 4):1055-62 Epub 2006/03/22.

12. Casadesus J, Low D. Epigenetic gene regulation in the bacterial world Microbiol Mol Biol Rev. 2006;70(3):830-56 Epub 2006/09/09.

13. Marinus MG, Lobner-Olesen A. DNA Methylation. EcoSal Plus. 2014;6(1):1-62. Epub 2014/05/01.

14. Murray IA, Clark TA, Morgan RD, Boitano M, Anton BP, Luong K, et al. The methylomes of six bacteria. Nucleic Acids Res. 2012;40(22):11450-62 Epub 2012/10/05.

15. Huo W, Adams HM, Zhang MQ, Palmer KL. Genome modification in Enterococcus faecalis OG1RF assessed by bisulfite sequencing and aingle-molecule real-time sequencing. J Bacteriol. 2015;197(11):1939-51 Epub 2015/04/01.

16. Egan ES, Waldor MK. Distinct replication requirements for the two Vibrio cholerae chromosomes. Cell. 2003:114(4):521-30 Epub 2003/08/28.

17. de Lorenzo V, Herrero M, Jakubzik U, Timmis KN. Mini-Tn5 transposon derivatives for insertion mutagenesis, promoter probing, and chromosomal insertion of cloned DNA in gram-negative eubacteria. J Bacteriol. 1990; 172(11):6568-72 Epub 1990/11/01.

18. Cohen NR, Ross CA, Jain S, Shapiro RS, Gutierrez A, Belenky P, et al. A role for the bacterial GATC methylome in antibiotic stress survival. Nat Genet. 2016;48(5):581-6 Epub 2016/03/22.

19. Takahashi N, Naito Y, Handa N, Kobayashi I. A DNA methyltransferase can protect the genome from postdisturbance attack by a restriction-modification gene complex. J Bacteriol. 2002;184(22):6100-8 Epub 2002/10/26.

20. Bottacini F, Morrissey R, Roberts RJ, James K, van Breen J, Egan M, et al. Comparative genome and methylome analysis reveals restriction/ modification system diversity in the gut commensal Bifidobacterium breve. Nucleic Acids Res. 2018;46(4):1860-77. Epub 2018/01/03.

21. Thelin KH, Taylor RK. Toxin-coregulated pilus, but not mannose-sensitive hemagglutinin, is required for colonization by Vibrio cholerae $\mathrm{O} 1 \mathrm{El}$ Tor biotype and O139 strains. Infect Immun. 1996;64(7):2853-6 Epub 1996/07/01.

22. Heidelberg JF, Eisen JA, Nelson WC, Clayton RA, Gwinn ML, Dodson RJ, et al. DNA sequence of both chromosomes of the cholera pathogen Vibrio cholerae. Nature. 2000:406(6795):477-83 Epub 2000/08/22.

23. Heyn H, Li N, Ferreira HJ, Moran S, Pisano DG, Gomez A, et al. Distinct DNA methylomes of newborns and centenarians. Proc Natl Acad Sci U S A. 2012; 109(26):10522-7 Epub 2012/06/13.

\section{Publisher's Note}

Springer Nature remains neutral with regard to jurisdictional claims in published maps and institutional affiliations.

Ready to submit your research? Choose BMC and benefit from:

- fast, convenient online submission

- thorough peer review by experienced researchers in your field

- rapid publication on acceptance

- support for research data, including large and complex data types

- gold Open Access which fosters wider collaboration and increased citations

- maximum visibility for your research: over $100 \mathrm{M}$ website views per year

At $\mathrm{BMC}$, research is always in progress.

Learn more biomedcentral.com/submissions 